\title{
Teoria e prática no curso de pedagogia
}

Giseli Barreto da Cruz

Universidade Federal do Rio de Janeiro

\section{Resumo}

Este estudo discute a complexa relação entre teoria e prática no curso de pedagogia a partir da visão de pedagogos primordiais. A pesquisa realizada voltou-se para um grupo de dezessete pedagogos que testemunharam, como alunos, os tempos iniciais de implantação do curso no Brasil e que se destacaram no campo acadêmico educacional como referenciais de formação e de pesquisa. Dois objetivos orientaram o estudo: levantar características do início do curso e das mutações por ele sofridas para analisar as implicações, resistências e avanços em sua trajetória, bem como sua importância no âmbito acadêmico; e obter, junto aos participantes, suas opiniões acerca da pedagogia como domínio de conhecimento e curso de graduação, para então interpretar sua posição no contexto do campo educacional brasileiro. Como principais interlocuções teóricas situam-se Dermeval Saviani (2007) e Jean Houssaye (2004). Metodologicamente, trabalhou-se com análise de depoimentos colhidos por meio de entrevistas semiestruturadas. A investigação revelou aspectos que evidenciam como o curso de pedagogia construiu-se entre nós e a posição conflituosa, porém importante, que ele ocupa no espaço acadêmico da educação. 0 trabalho apresenta uma análise parcial desses dados, abordando especificamente o histórico embate entre a teoria e a prática no curso em seus tempos iniciais e na atualidade, mediante as diretrizes curriculares de 2006.

\section{Palavras-chave}

Curso de pedagogia - Currículo - Teoria e prática.

Correspondência:

Giseli Barreto da Cruz

Universidade Federal do Rio de Janeiro

Faculdade de Educação - Sala 242

Av. Pasteur, 250

22290-240 - Rio de Janeiro/RJ

cruz.giseli@gmail.com 


\title{
Theory and practice in the education undergraduate course
}

\author{
Giseli Barreto da Cruz \\ Federal University of Rio de Janeiro
}

\begin{abstract}
This study discusses the complex relationship between theory and practice in the Education undergraduate course, from the view of primordial educators. The research has turned to a group of seventeen educators who witnessed the early days of the implementation of the Education course in Brazil as undergraduate students, and who excelled in the academic field of education as benchmarks for training and research. Two objectives have guided the study: to research on the features of the beginning of the course and on the changes it has gone through, to analyze the implications, resistances and advances in its history and its importance in the academic field; and to obtain from the participants their position on Education as a knowledge field and as a course to interpret their position in the context of the Brazilian educational field. The main theoretical dialogues were conducted with Saviani (2007) and Houssaye (2004). Methodologically, we worked with analysis of testimonials, collected through semi-structured interviews. The investigation revealed aspects that evidence how the Education course was constructed among us and the conflictive but important position which it occupies in the academic space of education. This article presents a partial analysis of these data, specifically addressing the historic clash between theory and practice in education courses in their early days and today, through the curriculum guidelines of 2006.
\end{abstract}

\section{Keywords}

Education course - Curriculum - Theory and practice.

Contact:

Giseli Barreto da Cruz

Universidade Federal do Rio de Janeiro

Faculdade de Educação - Sala 242

Av. Pasteur, 250 - Praia Vermelha

22.290-240 - Rio de Janeiro/RJ

cruz.giseli@gmail.com 
Este texto discute a complexa relação entre teoria e prática no curso de pedagogia a partir da visão de um grupo de pedagogos considerados primordiais. Trata-se de um trabalho elaborado com base em alguns dos dados construídos no âmbito de uma pesquisa de doutorado, cuja tese foi defendida em 2008.

A pesquisa voltou-se para pedagogos que cursaram pedagogia nas décadas de 1940, 1950 e 1960, vivenciando o curso seja em sua gênese, seja nas fases em que os primeiros marcos legais imprimiram mudanças em sua estrutura. Além disso, voltou-se também para pedagogos que ocupam posições dominantes no campo por deterem razoável capital científico (BOURDIEU, 1983). Por essa razão, tais pedagogos são considerados primordiais, visto que foram testemunhas dos tempos iniciais de implantação do curso no Brasil, como seus alunos, e também porque se destacaram no campo acadêmico da educação como referenciais de formação e de pesquisa.

Para trazer à baila a posição desses pedagogos a respeito do curso de pedagogia no Brasil, foram definidos dois objetivos para o estudo: levantar, junto aos investigados, aspectos característicos do início do curso e das mutações por ele sofridas, para analisar implicações, resistências e avanços em sua trajetória, bem como sua importância no âmbito acadêmico; e procurar obter qual é a concepção de tais profissionais acerca da pedagogia como domínio de conhecimento e como curso, a fim de mapear e interpretar sua posição no contexto do campo educacional brasileiro.

0 objeto do estudo apontou para uma defınição intencional e proposital, com critérios e perfis predefinidos, no sentido de assegurar a composição de um grupo representativo dos primórdios do curso e de seu campo. A abordagem metodológica foi a análise de depoimentos colhidos por meio de entrevistas semiestruturadas. Buscou-se obter informações sobre o início do curso, a formação nele recebida, as influências sentidas, as transformações ocorridas ao longo do tempo e de que modo os entrevistados percebem a pedagogia como campo de conhecimento, formação, atuação e intervenção social.

0 grupo de dezessete entrevistados é formado por catorze mulheres e três homens. Nove deles cursaram pedagogia na década de 1960; seis, na década de 1950; um, na década de 1940; e um, na década de 1930. Neste último caso, trata-se de um egresso do curso de história e geografia da Faculdade de Filosofia, Ciências e Letras da Universidade de São Paulo (1937-1940). 0 curso de pedagogia, como graduação, não se encontra em sua trajetória, o que ocasionou um desvio na composição do grupo de participantes da pesquisa. Todavia, seu percurso colocou-lhe na condição de quem viveu, de fato, os primórdios do curso de pedagogia no Brasil, posto que integrou o corpo docente da Faculdade de Filosofia, Ciências e Letras da Universidade de São Paulo quando o curso ali teve início, sendo o primeiro do Brasil. Por essa razão, entendeu-se que seu depoimento não poderia deixar de compor o quadro pretendido com o estudo.

Nove entrevistados são egressos de cursos oferecidos por instituições públicas de ensino superior e oito são egressos de instituições privadas. Do conjunto de instituições públicas, quatro entrevistados fizeram o curso de pedagogia na Universidade de São Paulo; dois, na Faculdade de Filosofia, Ciências e Letras de Rio Claro/SP; um, na Faculdade de Filosofia, Ciências e Letras de Marília/SP; um, na Faculdade de Filosofia, Ciências e Letras do Maranhão; e um, na Faculdade de Educação da Universidade Federal do Rio de Janeiro. Do conjunto de instituições privadas, dois entrevistados fizeram o curso de pedagogia na Pontifícia Universidade Católica do Rio de Janeiro; dois, na Pontifícia Universidade Católica de São Paulo; um, na Pontifícia Universidade Católica de Campinas; um, na Faculdade de Filosofia, Ciências e Letras de Goiás; um, na Faculdade de Filosofia, Ciências e Letras de Lins/SP; e um, na Universidade Sagrado Coração/SP. 
No que se refere à formação que precedeu o curso de pedagogia, apenas dois não passaram pela Escola Normal. Dentre os que passaram, seis alcançaram a cadeira prêmio, ingressando de imediato como professor primário efetivo do sistema de ensino do seu Estado. Apenas três deles fizeram um curso de aperfeiçoamento, complementar ao curso Normal, antes de ingressar no curso de pedagogia.

Boa parte do grupo reúne experiência como professor primário e/ou secundário. Doze atuaram como professores do primário e dez como professores do secundário na Escola Normal. No que se refere à atuação como professores do curso de pedagogia, todos trabalharam como formadores de pedagogos, oito deles iniciando essa experiência tão logo concluído o curso de pedagogia e um, em especial, como já mencionado, começando no início da década de 1940, quando o curso foi introduzido entre nós por meio do Decreto-Lei $n^{\circ} 1.190$, de 4 de abril de 1939.

Quase todos os entrevistados exerceram, em algum momento de suas trajetórias, funções referentes ao ofício de pedagogo: inspetor de ensino no âmbito da esfera federal; técnico de planejamento atuando em uma secretaria estadual de educação; curriculista no contexto dos sistemas estadual e federal de educação; diretor, coordenador pedagógico ou orientador educacional de escola.

Todos os entrevistados fizeram algum tipo de curso de especialização no Brasil e/ou no exterior. Onze passaram pelo mestrado em educação, catorze pelo doutorado e sete pelo pós-doutorado, sendo que alguns fizeram mais de um programa de estudo de pós-doutorado. Tal estudo foi desenvolvido no exterior, visto que a sua realização antecedeu a instalação e ampliação da pós-graduação em educação no Brasil. Alguns dos entrevistados, que não registram o título de mestre e o de doutor, alcançaram diretamente a condição de livre-docente pelo mérito de sua produção em uma época em que a pós-graduação não apresentava a estrutura que possui hoje.
A partir dessa descrição, salienta-se que os entrevistados constituem um grupo notada e propositalmente especial para atender aos objetivos do estudo, isto é, procurar saber como o curso de pedagogia é percebido por pedagogos que vivenciaram os primórdios do curso e que se destacaram por uma longa e expressiva trajetória como formadores e pesquisadores.

Da investigação emergiu uma série de aspectos que apontam para a forma como o curso veio se construindo entre nós e para a posição conflituosa, porém importante, que ele foi ocupando no âmbito do espaço acadêmico da educação. Este trabalho propõe-se a apresentar uma análise parcial de tais dados, abordando especificamente aspectos que concernem à problemática relação entre a teoria e a prática tanto no curso de ontem, quanto no de hoje, sempre na visão dos entrevistados.

\section{A difusa relação entre a teoria e a prática: histórico embate refletido na formação de professores}

Falar do início do curso de pedagogia sem falar do curso Normal parece ser algo difícil, visto que essa relação estabeleceu-se em todos os depoimentos, mesmo no caso das duas únicas entrevistadas que não ingressaram na Escola Normal. Ao serem interrogados sobre como foi o curso de pedagogia que fizeram, os entrevistados, em sua totalidade, mencionaram aspectos que focalizam diretamente 0 curso Normal, seja para explicar as motivações em tornar-se pedagogo, para comentar comparativamente o curso de pedagogia no tocante às disciplinas, à metodologia das aulas, aos professores e à sua própria finalidade, ou, ainda, para justificar a inserção como formador de professores primários, atividade cujo locus preferencial - e até então exclusivo - era a Escola Normal.

Segundo a grande maioria dos entrevistados, a formação para se tornar professor foi obtida por meio da Escola Normal, cursada por quinze deles. 0 curso de pedagogia parece 
não ter explorado suficientemente a prática desse ofício. Entretanto, a pedagogia, principalmente para aqueles que a cursaram nas décadas de 1940 e 1950, favoreceu uma sólida formação teórica, condição necessária, na visão dos entrevistados, para o processo de pensar, refletir, pesquisar e construir conhecimentos sobre a educação.

A partir da análise dos depoimentos, dois fatores sobressaíram-se. Um deles diz respeito ao modo diferenciado de relacionar a teoria e a prática. A afirmação Eu tive um curso Normal muito forte apareceu de forma recorrente, estimulando a busca, nos depoimentos, por possíveis indícios dessa força e por saber se esses indícios apareciam também quando a fala se referia ao curso de pedagogia. De modo geral, os entrevistados consideram que fizeram um bom curso Normal, por meio do qual aprenderam os fundamentos da educação e as metodologias necessárias para a realização do trabalho docente. Nessa mesma direção, eles consideram que também fizeram um bom curso de pedagogia, tendo a oportunidade de estudar em profundidade - expressão utilizada por alguns deles - disciplinas de cunho predominantemente teórico, ficando a prática restrita às disciplinas de didática e metodologia.

Nota-se, assim, que o curso de pedagogia assumiu, desde o início, uma feição bastante parecida com a do curso Normal no que diz respeito às disciplinas; no entanto, enfatizou mais a dimensão teórica do que a prática. Talvez essa difusa relação entre teoria e prática, no tocante aos dois cursos em questão, possa ser expressa da seguinte maneira: no curso Normal, predominou a ênfase na prática com muita teoria, ao passou que, no curso de pedagogia, predominou a ênfase na teoria com pouca prática.

Entretanto, é importante destacar que um dos entrevistados chama atenção, em seu depoimento, para o fato de que a prática predominante no curso Normal que frequentou mostrou-se demasiadamente formalista, centrando-se mais em aspectos relativos à preparação de aula. A aprendizagem sobre como alfabetizar e ensinar aritmética, entre outras, não foi explorada. A fala dessa entrevistada merece atenção tanto pelo fato de ela ser dissidente, no sentido de que nenhum outro depoente focalizou essa dimensão da prática, como pelo fato de essa visão ter sido apresentada por uma aluna do curso que, mais tarde, tornou-se pesquisadora da história do ensino Normal. Vejamos o que ela própria diz:

Eu lembro que o ensino Normal era meio formalista, como é que se faz um diário de classe, como é que se faz um plano de aula... Eu estudei história do ensino Normal, você sabe disso. Essa parte metodológica de que tanto se fala, da prática de ensino, eu não consigo ver nos antigos cursos Normais, nem naqueles que eu tomei como objeto de estudo. (Entrevistada déc. 1960)

Ainda assim, no contexto do estudo realizado, a ênfase na dimensão prática do curso Normal constituiu-se como o principal indício da força desse curso para os entrevistados. Mesmo que a prática tenha sido restrita, parece que ela não deixou de ser o mote principal do curso, para o qual convergiram todos os demais estudos de fundamentação que se tornaram decisivos no processo de fazer-se professor, tal como se pode depreender da fala a seguir:

A base de criação da minha cultura peda-
gógica se deu no curso Normal. Do ponto
de vista estruturalmente pedagógico, as
questões de sala de aula, prática de ensino,
didática foram trabalhadas no Normal. No
curso de pedagogia não houve nenhuma
referência significativa a esse respeito.
(Entrevistado déc. 1950)

No caso do curso de pedagogia, a força recaiu sobre os estudos teóricos. Porém, se, por um lado, essa força fez calar a prática, por outro, favoreceu uma compreensão mais crítica dos fatos sociais e, portanto, da prática pedagógica. Reside nesse ponto o outro fator destacado 
durante as análises, o qual diz respeito à força dos estudos teóricos sobre a educação.

Do conjunto de depoimentos, chama atenção, inicialmente, a fala de duas entrevistadas da década de 1950 que utilizaram a expressão pensador, deixando antever que o foco principal do curso estava ajustado nessa perspectiva.

0 bacharelado tinha a missão de formar o cientista, o pensador da educação. (Entrevistada déc. 1950)

Qual foi o espírito do curso de pedagogia que eu fiz naquela época? Era de um pensador em educação. (Entrevistada déc. 1950)

As duas entrevistadas fizeram o curso em fins dos anos 1950 e início dos anos 1960, quando vigorava o primeiro marco legal. Nesse período, a estrutura do curso considerava uma série de disciplinas de fundamentos, predominando, de fato, a dimensão teórica. Entretanto, no tocante à finalidade do curso, buscava-se formar, no bacharelado, o técnico de educação e, na licenciatura, o professor da Escola Normal. 0 propósito de formar um pensador em educação, capaz de teorizar sobre ela e propor ações referentes aos processos por ela desencadeados, não se manifestou com muita clareza no contexto da lei, mas parece ter encontrado alcance no contexto do curso.

Carmem Bissolli da Silva (1999) discute essa questão, pontuando que, em sua organização inicial, o curso de pedagogia previu a formação do bacharel sem apresentar elementos que caracterizassem o trabalho a ser por ele exercido. A finalidade do bacharelado era identificada no bojo daquelas definidas para a Faculdade Nacional de Filosofia, que se dirigia ao preparo da intelectualidade que exerceria as altas atividades culturais no país. Porém, o diploma de bacharel em pedagogia conferiria ao portador, a partir de $1^{\circ}$ de janeiro de 1943 - quando, subentende-se, a primeira turma estaria formada -, a possibili- dade de ocupar cargos de técnicos de educação do Ministério de Educação. Segundo Bissolli da Silva (1999), organizou-se um curso que não incluiu o mínimo de componentes curriculares necessários para a formação de um profissional, cujo perfil não estava claro.

Para um dos entrevistados da década de 1950, os estudos desenvolvidos durante o curso de pedagogia foram determinantes para a continuidade de sua trajetória, influenciando na definição de seu objeto de pesquisa e na implementação do trabalho que empreendeu para levá-la a efeito.

Estudei muita teoria no curso de pedagogia. A começar por um curso de sociologia que fiz com o professor Antônio Cândido. Foi com ele que eu li As regras do método sociológico, de Durkheim. [...] 0 curso de pedagogia, com todos esses professores que eu indiquei (Antônio Cândido, Fernando de Azevedo, Laerte Ramos de Carvalho, Roque Spencer Maciel de Barros...), me deu uma formação teórica muito sólida. [...] Quando fui pra Araraquara para dar aula de pedagogia geral no curso de pedagogia, não sabia direito o que que era. Foi, então que comecei a pensar um esquema teórico de análise em três níveis: nível da sociedade, nível do sistema escolar e nível técnico-pedagógico. Eu tentei pensar cada um desses níveis com base no que havia estudado e articular um com o outro. [...] Qual era a minha preocupação? Na época, a história da educação era mais ou menos considerada como disciplina autônoma e era muito fraquinha ainda. Estava começando a se desenvolver. Então, eu pensei que não tinha sentido desligar educação, história da educação escolar e sociedade. Por outro lado, eu considerava, também, que não adiantava você elaborar o que se chama teoria, doutrina ou pensamento educacional, se ele não tivesse condições de ser operado no chão da fábrica, ou 
seja, na sala de aula. Daí o nível técnico-pedagógico. [...] 0 que eu pretendia era trabalhar com meus alunos no nível desse pensamento e no nível do que consegue realizar, na prática, esse pensamento. (Entrevistado déc. 1950)

0 primeiro aspecto que emerge desse depoimento diz respeito aos professores. Uma possível razão para a ênfase teórica do curso de pedagogia nessa época reside no perfil de seu corpo docente. 0 entrevistado refere-se a grandes nomes da educação brasileira. Ele teve o privilégio, assim como boa parte dos demais, de ser aluno de pessoas expoentes. É importante atentar que muitos desses professores, ainda que bem formados e bem situados no contexto acadêmico, não conheciam o chão $d a$ fábrica, expressão utilizada pelo entrevistado. A falta de contato com o trabalho pedagógico realizado na escola forçosamente destaca a dimensão teórica, domínio de investimento desses professores.

O segundo aspecto que merece consideração no depoimento em análise tem relação com o modo como a teoria estudada transforma-se em uma importante ferramenta diante de situações novas e desafiantes, tal qual aquela que envolveu o entrevistado no início de sua trajetória de formador de pedagogos. Sem muita clareza acerca de como caminhar com uma disciplina intitulada teoria geral da pedagogia, ele resolveu pensar um referencial teórico próprio. Certamente, as condições para investir em tamanho desafio não se restringiram às leituras realizadas e às experiências obtidas durante o curso de pedagogia, mas outras vivências também contribuíram para isso. 0 esquema teórico mencionado integra sua tese de livre-docência, cujo trabalho tornou-se um marco na história da educação brasileira. Todavia, ele não deixou de ressaltar o lugar ocupado pelo curso de pedagogia em sua formação. Por essa via, parece mesmo que a força de seu curso movia-se em torno do ato de pensar, teorizar e refletir sobre o processo educacional.
Por último, o depoimento destacado deixa entrever um aspecto bastante importante dessa dimensão teórica: a preocupação com a prática. Se, por um lado, a força teórica faz silenciar a prática, por outro, essa força adquire mais sentido e, portanto, ainda mais força quando se materializa no contexto da prática. Repetindo o que disse o entrevistado,

0 que eu pretendia era trabalhar com meus alunos no nível desse pensamento e no nível do que consegue realizar, na prática, esse pensamento. (Entrevistado déc. 1950)

Vemo-nos, então, diante do problema fundamental da pedagogia (SAVIANI, 2007), que, por definição, é, em si mesmo, constitutivo dessa complexa relação: pensar e praticar a educação. Para Dermeval Saviani (2007), a pedagogia desenvolveu-se a partir da estreita relação que estabeleceu com a prática educativa, ora sendo assumida como teoria dessa prática, ora sendo identificada como o modo por meio do qual essa prática se estabeleceria.

Segundo o autor, da relação teoria-prática derivam duas grandes tendências pedagógicas que podem ser assim sumariadas: de um lado, a prática subordinada à teoria, em que prevalecem as teorias do ensino (como ensinar) e incluem-se as diversas vertentes de pedagogia tradicional; de outro lado, a teoria subordinada à prática, em que predominam as teorias da aprendizagem (como aprender) e situam-se as variadas experiências da pedagogia nova.

Saviani (2007), que se dedica a pesquisar as perspectivas históricas e teóricas do espaço acadêmico da pedagogia no Brasil, sinaliza, com base em Suchodolski (1978), que as concepções tradicionais, sustentadas em diferentes aportes, como os de Platão, Comênio, Kant, Fichte, Hegel e Herbart-Ziller, convergem para uma teorização sobre o ensino, assumindo a formação intelectual como o objeto central do trabalho pedagógico. As concepções renovadoras, fundamentadas em Rousseau, Pestalozzi, Froebel, Kierkegaard, Stirner, Nietzsche e Bergson, chegando aos 
movimentos do escolanovismo, das pedagogias não diretivas, da pedagogia institucional e do construtivismo, em contraposição à tendência anterior, assumem a aprendizagem como o objeto principal do trabalho pedagógico e, portanto, de suas teorizações.

As duas tendências mencionadas contribuem para reforçar o problema que envolve a equação teoria-prática para a pedagogia, no sentido em que cada uma assume uma dimensão desse binômio como nuclear de sua concepção (tradicional - teoria / renovada - prática), acentuando o fosso existente entre ambas, cuja superação representa condição para afırmação da própria pedagogia.

0 trabalho pedagógico no contexto escolar e fora dele é amplamente marcado pela influência da visão tradicional e também pelo forte desejo de sua superação por meio da influência renovadora. Busca-se a superação da teoria pela prática, numa perspectiva de oposição. Nesses termos, teoria e prática são historicamente construídas de forma dissociada e teoricamente consideradas partes indissociáveis da pedagogia, constituindo-se, paradoxalmente, no próprio dilema pedagógico.

Para Saviani (2007), teoria e prática são aspectos dialeticamente distintos e fundamentais da experiência humana, definindo-se um em relação ao outro: "a prática é a razão de ser da teoria, o que significa que a teoria só se constituiu e se desenvolveu em função da prática que opera" (p. 108). Nesse sentido, o autor defende que a prática se tornará mais consistente quanto mais sólida for a teoria que lhe serve de fundamento, sendo ambas, portanto, opostos que se incluem.

Para superar as divergências teórico-práticas provocadas pelas duas grandes tendências pedagógicas que trataram "teoria e prática como pólos opostos mutuamente excludentes” (p. 109), Saviani (2007) sugere a emergência de outra formulação, centrada na unidade compreensiva da teoria e da prática.

Nessa nova formulação a educação é entendida como mediação no seio da prática social global. A prática social se põe, por- tanto, como o ponto de partida e o ponto de chegada da prática educativa. (p. 110)

Por esse caminho, a prática social constitui-se no principal mote do trabalho pedagógico, do qual emergirão, teórica e praticamente, as questões a serem problematizadas, os instrumentos para seu estudo e elucidação, e as ideias para aplicação à própria vida dos sujeitos envolvidos nesse processo, favorecendo, assim, a unidade teoria-prática.

A análise de Saviani leva-nos à de Jean Houssaye (2004). Esse autor defende que a pedagogia representa um saber específico, que pressupõe a reunião mútua e dialética da teoria e da prática educativas pela mesma pessoa. A articulação teoria-prática é de tal modo determinante e constitutiva da pedagogia, que um prático por si só não é um pedagogo, mas um usuário de sistemas pedagógicos, assim como o teórico da educação também não se constitui em um pedagogo, porque pensa a ação pedagógica. Na definição de Houssaye (2004), pedagogo é um prático-teórico da ação educativa; é alguém que, ao teorizar sobre a educação, analisa o fato educativo buscando formular proposições para sua prática.

Considerar a relação teoria-prática como pedra angular da construção da pedagogia, reconhecendo nela uma abordagem específica, não significa desconsiderar que a prática está, de algum modo, presente entre os teóricos, ou que o pensamento teórico baliza a prática. Significa, isto sim, reconhecer e defender que a prática, constituindo a pedagogia, não pode ser algo meramente projetado, da mesma forma que a teoria pedagógica não pode ser apenas algo tomado de outros. Tal concepção pressupõe que a pedagogia se constrói a partir de uma proposta prática e de uma teoria da situação educativa referida a essa prática. Há saber nessa composição. Em outras palavras, se a pedagogia for vista como assentada apenas no saber de outros campos, nutrindo-se apenas deles, ela renuncia a si mesma, recusando sua própria natureza. 
Historicamente, a pedagogia desfalece na medida em que é assumida como objeto de várias outras disciplinas. A princípio, a filosofia coloca-se como a voz teórica da pedagogia. Posteriormente, a psicologia fundamenta a pedagogia, situando-a como ciência da educação. Em seguida, um conjunto de disciplinas firma-se como a base teórica da pedagogia, anunciando-se como ciências da educação. Esse processo de recolocação da pedagogia dá-se em um contexto de desagregação, uma vez que, de teoria prática, a pedagogia reduz-se a uma prática de aplicação de teorias emprestadas. Todavia, é importante atentar que, de início, a ciência e, posteriormente, as ciências da educação justificam-se em grande parte para favorecer a sistematização de saberes rigorosos sobre a educação, o que, por mérito, representa a própria especificidade da pedagogia.

Houssaye (2004), no contexto de sua argumentação, chama atenção para a necessidade de não se desqualificar a pedagogia pelo fato de sua concepção pressupor uma indissolúvel ligação com a prática. Para o autor, a pedagogia "produz incontestavelmente um saber pedagógico além dos saberes práticos" (p. 25).

0 estudo realizado evidencia que a difusa relação entre a teoria e a prática manifesta-se no curso de pedagogia desde seu início, refletindo-se na formação de professores e acentuando uma questão fundamental para o campo: se a prática é um elemento conceitual constituidor da pedagogia, conforme problematizam Saviani (2007) e Houssaye (2004), como não ter encontrado entrada em seu próprio curso?

\section{Atuais diretrizes curriculares para o curso de pedagogia:} possibilidades e limites teóricos e práticos para a formação de professores

Saltando dos anos iniciais do curso de pedagogia para um período mais recente, nota-se que a década de 1980 foi emblemática para o debate sobre a recontextualização da educação brasileira. 0 curso, no âmbito das discussões sobre a formação de professores e demais profissionais de educação, foi alvo de incontáveis críticas, fazendo crescer o movimento em torno da reformulação de seu currículo. 0 processo de gestação das atuais diretrizes curriculares para o curso de pedagogia foi bastante longo e difícil, tal como discutem Aguiar e Melo (2005), Kuenzer e Rodrigues (2006), Libâneo (2006), Tanuri (2006), Franco, Libâneo e Pimenta (2007), Saviani (2007) e Sheibe (2007). Uma ideia, em especial, ganhou fôlego no debate travado, principalmente pela posição das entidades e associações de docentes: a docência como base da identidade nacional de todo educador.

Com a promulgação da Lei de Diretrizes e Bases da Educação Nacional (Lei $\mathrm{n}^{\circ}$ 9.394/1996), várias reformas foram empreendidas, tal como aconteceu em fins dos anos 1960 e início dos anos 1970; entre elas, a indicação para alteração dos currículos dos cursos de graduação. Com a autorização do Conselho Federal de Educação, várias instituições passaram a experimentar mudanças em seus cursos de pedagogia, incorporando a formação do docente para a primeira etapa do ensino fundamental, até então responsabilidade exclusiva do curso Normal de nível médio, e atenuando a força das habilitações dirigidas à formação do especialista, independentemente do preconizado pelo Parecer CNE n 252/1969, ainda vigente. Nesse sentido, o curso de pedagogia, que ao longo de sua trajetória esteve apartado da escola primária, passa a enfatizar essencialmente a docência própria ao seu contexto.

Nesse cenário de disputas, o referido curso viu-se bastante ameaçado, uma vez que a LDB introduziu o curso Normal Superior como instância responsável pela formação de docentes para a educação infantil e para a primeira etapa do ensino fundamental, ênfase que a pedagogia tentava tomar para si. A polarização estabelecida dificultou a definição de uma proposta razoavelmente consensual entre os educadores no que tange às diretrizes curriculares.

No decorrer de uma caminhada bastante longa de discussão sobre o que seriam as diretrizes 
curriculares para o curso de pedagogia, prevaleceu o tom nada consensual, manifesto pelas posições divergentes em jogo. Paradoxalmente, a docência como base de formação fez emergir o consenso e o dissenso, sendo o próprio pomo da discórdia.

0 curso de pedagogia passa a ser um curso de licenciatura com foco na formação inicial para o exercício da docência na educação infantil e nos anos iniciais do ensino fundamental; nos cursos de ensino médio, na modalidade Normal; em cursos de educação profissional na área de serviços e apoio escolar; e em áreas nas quais sejam previstos conhecimentos pedagógicos.

A formação por ele oferecida deve abranger, integradamente à docência, a participação da gestão e avaliação de sistemas e instituições de ensino em geral, a elaboração, a execução e o acompanhamento de programas, bem como de atividades educativas em contextos escolares e não escolares, podendo contemplar uma diversidade de temas.

Quanto às habilitações responsáveis pela formação de especialistas para as atividades de orientação educacional, administração escolar, supervisão e inspeção de escolas e sistemas de ensino, o documento inicialmente previu, em seu artigo 10 (Parecer CNE/CP n ${ }^{\circ}$ 5/2005), que elas entrariam em regime de extinção a partir do período letivo seguinte à publicação da Resolução, e, no artigo 14, que a formação dos demais profissionais da educação - no caso, pedagogos não docentes ou especialistas - deveria ser realizada em cursos de pós-graduação, especialmente os estruturados para esse fim, abertos a todos os licenciados e não só aos egressos do curso de pedagogia. No entanto, tal proposição contrariou o que dispõe a LDB em seu artigo 64. Por conta da contraposição mencionada, o Parecer CNE/CP n 5/2005, apesar de aprovado, foi reencaminhado pelo Ministério da Educação ao Conselho Nacional de Educação para reexame da matéria. Assim, o Parecer teve seu artigo 14 retificado e passou a assegurar a formação de profissionais da educação prevista no artigo
64 da LDB, sem, no entanto, apontar, no corpo do texto de fundamentação das diretrizes, indicativos de estruturação do curso nessa direção. Em face dessa situação, fica patente, nas diretrizes, a ambiguidade criada: uma proposta de curso para formar essencialmente o pedagogo docente, com direito assegurado em lei de formar também o pedagogo não docente, sem que a base dessa formação esteja prevista.

E como se posicionaram os pedagogos primordiais entrevistados sobre a nova configuração do curso de pedagogia, sobretudo no que diz respeito à complexa relação entre teoria e prática? Dos entrevistados, quatro não se manifestaram, alegando que se distanciaram das discussões a respeito desse tema e que não conheciam o documento. Quanto aos demais, o que é possivel depreender de seus depoimentos são posições que não podem ser simplesmente enquadradas nos quesitos a favor ou contra, pois deixaram entrever nuanças favoráveis a determinados aspectos e contrárias a outros.

Da análise dos depoimentos, três aspectos indicaram pontos de relevância, designados da seguinte forma: o afastamento da teoria, o não lugar das habilitações e a docência como base de formação.

\section{0 afastamento da teoria}

Quase a totalidade dos entrevistados manifestou preocupação com a formação a ser oferecida pelo curso, considerando a diversidade de enfoques possíveis. No cerne dessa preocupação situa-se a dificuldade em favorecer o estudo teórico, condição essencial, na visão desses entrevistados, para pensar, propor, implementar e avaliar o trabalho pedagógico. A fala a seguir é representativa dessa visão:

Como o pedagogo em formação aprenderá filosofia em 75 horas? Considero que as diretrizes empobreceram a formação do pedagogo como aquele que precisa ter um forte domínio dos conhecimentos pedagógicos. (Entrevistada déc. 1950) 
Pelo que se pode captar dos depoimentos, parece que, para os entrevistados, o afastamento da teoria é inevitável, visto que o curso ficou sobrecarregado de ênfases formativas, de um lado, acentuando a fragmentação já existente e, de outro, empobrecendo as possibilidades de abordagem teórica. Segundo declararam os entrevistados, será preciso fazer muito com pouco, tendendo a aligeirar ainda mais a formação, além do estilo enciclopédico que provavelmente dominará a organização dos cursos.

Acho que a formação teórica, necessária para pensar a educação e fazer avançar o pensamento pedagógico, se perdeu, se esfacelou com a fragmentação do curso. (Entrevistada déc. 1960)

0 afastamento da teoria faz avançar a prática? Seria o avesso dos primórdios do curso? Uma das vantagens observadas nas diretrizes por alguns dos entrevistados tem relação com a prática. Uma carga horária maior facilitaria um conhecimento mais apurado do campo de atuação. Entretanto, a falta de fundamentos teóricos para refletir sobre esse campo e sua prática pode comprometer o trabalho pedagógico a ser desenvolvido. Trata-se de uma equação difícil de ser resolvida para os entrevistados.

Eu acho que tem uma vantagem, que é a de ter ampliado um pouco mais a carga horária para as atividades práticas, porém muita disciplina dificulta o estudo aprofundado, necessário para pensar a prática. (Entrevistada déc. 1960)

Se antes prevaleceram poucas disciplinas, com carga horária ampliada, favorecendo o estudo aprofundado, agora prevalecem muitas disciplinas, com carga horária reduzida, viabilizando apenas uma visão geral sobre um tema central, sem grandes aprofundamentos teóricos e com uma parte prática mal resolvida pelos estágios propostos.

\section{0 não lugar das habilitações}

A análise dos depoimentos evidencia que, para os entrevistados, ter ou não ter habilitação no curso de pedagogia não é o ponto crítico do problema, assim como o contexto mais adequado para formar o especialista parece ser mesmo o da pós-graduação. Portanto, se as habilitações irão acabar e se o pedagogo deixará de ser chamado de especialista, isso representa, de alguma forma, um avanço. Para eles, o problema é mais complexo, pois diz respeito à base da formação. Ser professor é ser professor; ser pedagogo é ser pedagogo. Professor ensina; pedagogo faz pedagogia. Se o curso de pedagogia forma o professor, quem formará o pedagogo? Então, o curso deixará de ser de pedagogia e passará a ser de formação de professores? A fala, a seguir, focaliza essa problemática:

Se a pedagogia ficar reduzida à atividade de formação do professor, perderá um espaço único na universidade de trabalhar a educação como objeto de estudo. [...] Quanto às habilitações, eu penso que elas deveriam ter terminado mesmo, mas não o trabalho do pedagogo fora da sala de aula. (Entrevistada déc. 1960)

Sobre a relação entre habilitação e especialização, para alguns dos entrevistados, o pedagogo habilitado, antes das diretrizes, como especialista para trabalhar com professores, concebendo e implementando processos de formação continuada no contexto do próprio estabelecimento de ensino, deveria ser formado no nível da pós-graduação.

0 pedagogo que trabalha com os professores, como responsável pela sua formação continuada, que mobiliza os processos pedagógicos da escola como um todo, deve ser formado no nível da pós-graduação, porque, assim, pressupõe que ele tenderia a ter uma experiência mais consolidada na 
sala de aula. É muito difícil um pedagogo ser orientador de professores sem nunca ter passado pela experiência de professor. Assim como é muito difícil um pedagogo ser orientador de educadores populares sem nunca ter sido um educador popular. (Entrevistada déc. 1950)

A fala dessa entrevistada leva-nos ao próximo eixo de discussão. Se o trabalho do pedagogo volta-se essencialmente para a escola como um todo, isto é, para a concepção, implementação e avaliação da prática pedagógica por ela desenvolvida, para a articulação do currículo e sua materialização na sala de aula e fora dela, para a formação em serviço de seus profissionais, para as parcerias estabelecidas e, enfim, para a organização e gestão articuladora da ação educativa na escola, como também em outros contextos educativos, parece que a docência representa uma condição imprescindível. Tal como definido pelo movimento dos educadores dirigido pela ANFOPE (Associação Nacional pela Formação dos Profissionais da Educação), a docência deve ser a base de formação. Contudo, tomá-la como base significa fazer dela o início, o meio e o fim da formação do pedagogo? Saem as habilitações, responsáveis por conferir ao pedagogo credenciais para a realização desse trabalho mais abrangente, e fica a docência, entendida não no sentido de desenvolvimento de aulas, mas no sentido de íntima relação com o trabalho pedagógico em suas diferentes variações. Como se posicionam os entrevistados acerca dessa perspectiva?

\section{A docência como base de formação}

Esse foi um tema que mobilizou os entrevistados, não por eles discordarem que o pedagogo também precisa ser um professor, mas pelo fato de o pedagogo não poder ficar subsumido no trabalho do professor. Há muitos complicadores aqui, visto que um manifesto a favor dos pedagogos (HOUSSAYE et al., 2004) pode, nesse caso, dar a entender que pedagogo é mais do que professor, que o trabalho docente deve estar subordinado ao do pedagogo, ou, ainda, que o professor não pode desempenhar as funções até então pensadas para o pedagogo no contexto da escola, do sistema e de outros espaços educativos.

$\mathrm{Na}$ visão dos entrevistados, a ideia de docência como um dos princípios formativos do pedagogo é, de modo geral, bastante razoável, representando um ponto consensual. Entretanto, há variações nessa visão que merecem destaque e que podem ajudar a entender os complicadores sinalizados.

Do grupo de entrevistados, cinco, em especial, concordam, sem hesitação, com o princípio da docência como base de formação do pedagogo. Vejamos o que alguns dizem a esse respeito:

Do meu ponto de vista a docência é fundamental. Pedagogo que não é ou foi professor dificilmente conseguirá desenvolver com êxito seu trabalho na escola e fora dela. (Entrevistada déc. 1960)

Isso eu sempre defendi! Eu não sei até que ponto eu fui uma das precursoras de tentar colocar essa ideia na prática. Quando participava do grupo de São Paulo que discutia e propunha alterações para o currículo do curso de pedagogia, lembro-me de ter colocado essa ideia no papel, defendendo a formação docente como base para depois chegar na formação do especialista em outros termos. (Entrevistada déc. 1960)

Há entrevistados que, mesmo concordando com a ideia de a docência ser a base formativa do pedagogo, fazem questão de sublinhar que ela é necessária, mas não suficiente.

Em todos os encontros sobre este assunto e em todos os textos que tenho escrito sobre isto, eu digo que não nego a importância de que a pedagogia cuide da docência e 
forme para a docência, já que o campo da educação inclui o campo do ensino e da aprendizagem, mas só isto não! (Entrevistada déc. 1960)

Para outros entrevistados, a docência é uma opção, mas não necessariamente a base de formação. Tal posição é claramente exposta na fala a seguir:

A docência é uma das opções formativas, mas a base tem que estar voltada para a essência da pedagogia, enquanto ciência da educação. 0 curso é de pedagogia para formar o pedagogo. Que o pedagogo deve saber sobre a docência é uma coisa, porque isto tem relação com a pedagogia. Agora, que ela é sua base é outra, porque sendo ela sua base, a pedagogia propriamente dita corre o risco de não ser considerada no seu próprio curso. (Entrevistada déc. 1960)

Como se pode ver, a complexidade parece não residir na docência, mas no receio de secundarização da própria pedagogia, uma vez que a docência, como base, passa a ser o eixo estruturante de todo o curso. Nesse sentido, um aspecto focalizado pelos entrevistados, inclusive por aqueles que não veem problema na docência como base de formação do pedagogo, diz respeito ao conceito de docência subjacente no texto das diretrizes curriculares para o curso de pedagogia.

Segundo o que consta nos pareceres e na resolução das diretrizes curriculares, a docência é compreendida como ação educativa e processo pedagógico metódico e intencional, desenvolvido nas diversas relações próprias da pedagogia, por meio da articulação entre conhecimentos científicos e culturais, e valores éticos e estéticos inerentes aos processos de aprendizagem, socialização e construção de conhecimentos. Em suma, trata-se de uma concepção bastante larga e ampliada de docência, buscando não encerrá-la no contexto da sala de aula, mas transcendê-la para todo o contexto de onde emanam trabalhos pedagógicos. Ao conceituar a docência dessa forma, o texto deixa entrever que a pedagogia ficou restrita à docência, enquanto esta se ampliou, abarcando a pedagogia. Tal concepção gera imprecisão quanto ao objeto próprio da pedagogia, visto que a compreensão genérica da docência permitiria assumir a pedagogia por dentro dela, e não o contrário.

Maria Amélia Franco, José Carlos Libâneo e Selma Garrido Pimenta (2007) posicionam-se acerca dessa questão, defendendo que o curso de pedagogia não pode ter a docência como base. Para eles, todo trabalho docente é trabalho pedagógico, mas nem todo trabalho pedagógico é trabalho docente (p. 84). A defesa em torno da concepção de que o trabalho pedagógico incorpora a docência, porém vai além dela, encontra entrada entre os pedagogos entrevistados. As controvérsias acentuam-se quando os autores mencionados afirmam que "um professor é um pedagogo, mas nem todo pedagogo precisa ser professor" (p. 84). Nesse caso, para os entrevistados, em sua maioria, é fundamental que o pedagogo seja também um professor.

A análise dos depoimentos, confrontada com a análise da literatura acadêmica a esse respeito e com a prática pedagógica construída ao longo de nossa trajetória, leva-nos à seguinte posição: o trabalho docente é essencialmente um trabalho pedagógico, mas não só ele. Outros trabalhos também são essencialmente pedagógicos, sem serem necessariamente trabalhos de docentes. Entretanto, a docência, dada sua natureza estritamente pedagógica, desencadeia outras frentes de trabalho pedagógico (gestão, formação, pesquisa, teorização sobre a educação etc.), devendo, então, ser assumida como ponto de partida para sua realização, e não como ponto final. Nessa perspectiva, é bom que o pedagogo seja um docente, mas seu trabalho transcende o da docência, sem, por isso, ser superior a ela.

Ainda em relação à docência como base de formação do pedagogo, observa-se, na fala de alguns dos entrevistados, a preocupação com 
o destino do curso de pedagogia. As diretrizes, mais do que defenderem a docência como base, defınem a docência como finalidade precípua do curso. Nessa direção, o curso de pedagogia tende a assumir o perfil concebido para o curso Normal Superior. Mais uma vez, a identidade sempre questionada da pedagogia se forjaria a partir da identidade de outra entidade. Além disso, ressalta-se o conflito entre as diretrizes curriculares do curso de licenciatura em pedagogia e as dos cursos de formação de professores. A fala adiante é bastante reveladora desse tipo de inquietação:

A maioria dos cursos de pedagogia já se transformou no que a gente poderia chamar de um tipo de Escola Normal Superior. [...] Se o pedagogo vai ser um professor de $1^{\mathrm{a}}$ a $4^{\mathrm{a}}$ séries ou se ele vai ser um pensador em educação, é diferente. Não que o professor de $1^{\mathrm{a}}$ a $4^{\mathrm{a}}$ séries não pense educação, mas ele precisa ter outro tipo de formação. Não dá pra você formar um cirurgião sem ensinar a ele a instrumentação. É a mesma coisa com o professor, ele é um profissional que precisa ser formado com a instrumentação devida para a sua prática. Então, nós ficamos com uma coisa híbrida, que nem forma o professor, nem o pedagogo direito. [...] Eu não sei como vai ser, porque quem forma o professor tem que obedecer às diretrizes para a formação de professores, mas ao mesmo tempo você tem uma diretriz específica para o curso de pedagogia, que basicamente só forma o professor. (Entrevistada déc. 1950)

Pelo que se pode depreender dos dados apresentados e da análise desenvolvida, a forma assumida pelo curso a partir de suas atuais diretrizes curriculares é bastante controvertida. A formação do professor passa a representar o eixo central do curso, enquanto as demais atividades atinentes ao pedagogo são insuficientemente definidas. Os pedagogos entrevistados percebem nas diretrizes um esvaziamento do que é próprio da pedagogia.
0 descontentamento dos entrevistados não recai sobre as habilitações ou os especialistas, questão que mobilizou tanta discussão ao longo do debate que acompanhou o processo de elaboração do documento das diretrizes curriculares, mas sobre a ausência da própria pedagogia. A docência como base de formação também não parece ser o grande problema. Este se revela no desaparecimento do conhecimento pedagógico do seu próprio curso. Os aspectos constitutivos do campo teórico-prático da pedagogia não foram suficientemente contemplados no documento, acentuando a complexa relação entre teoria e prática e seus efeitos para a formação docente.

\section{Conclusão}

Olhar o curso de pedagogia no Brasil com a visão dos pedagogos entrevistados, atentando para aspectos característicos dos tempos iniciais do curso e para as mudanças por ele sofridas, para analisar implicações, resistências e avanços em sua trajetória, possibilitou captar aspectos, dilemas, desafios e possibilidades que certamente são contributivos ao processo mais amplo de compreensão do papel da pedagogia na formação de professores.

Neste artigo, a partir de uma pequena porção dos dados obtidos com a pesquisa, a ênfase da análise recaiu sobre a relação entre a teoria e a prática. Buscou-se focalizar aspectos históricos da gênese do curso de pedagogia e de diferentes momentos que marcaram sua trajetória, a fim de favorecer o debate sobre os desafios que espreitam os profissionais da área em relação à teoria e à prática, conexão bastante problemática no campo da formação.

As análises apresentadas evidenciam que os fundamentos teóricos, em comparação com a experiência prática, obtiveram maior peso na estrutura e na prática curricular do curso. Situar o papel da teoria no curso representou sublinhar a multiplicidade de saberes que constituem a pedagogia, dada sua estreita relação com diferentes frentes disciplinares, sinalizando ora a 
força, ora a própria fraqueza da pedagogia. Se a multiplicidade de estudos teóricos fez crescer o seu domínio de conhecimento, igualmente contribuiu para engendrar um quadro de dispersão da própria pedagogia, dificultando a afırmação de um estatuto teórico específico.

A travessia do passado para o presente, de modo a focalizar o curso de hoje, com base nas diretrizes curriculares homologadas pelo Conselho Nacional de Educação (CNE) no ano de 2006, permitiu ver que o problema entre a teoria e a prática permanece em pauta, ainda que com outras nuances. A multiplicidade de saberes que constituem a pedagogia correrá o risco de dispersar-se ainda mais, enfraquecendo a formação teórico-prática em face da diversidade de enfoques formativos que passou a vigorar no curso.

Entendemos que a pedagogia requer formulações próprias a partir das diversas áreas que lhe são constitutivas. Dessa forma, nem só a teoria, nem só a prática, mas a reunião mútua e dialética de ambas é o que faz emergir um pedagogo.

Segundo Houssaye (2004), um pedagogo não pode ser compreendido como um prático ou como um teórico, visto que ele se faz no entremeio dessa relação. A conexão entre a teoria e a prática deve ser contínua e qualquer perspectiva de fosso entre as duas não deve subsistir. Assim, é um equívoco considerar que um prático é um pedagogo; ele nada mais é do que um usuário de sistemas pedagógicos. Da mesma forma, também é um engano tomar o teórico da educação como um pedagogo, já que não basta pensar sobre o processo pedagógico.

Só será considerado pedagogo aquele que fizer surgir um plus na e pela articulação teoria-prática em educação. Esse é o caldeirão de fabricação pedagógica. (p. 10)

Diante do dilema historicamente construído em torno da teoria e da prática no curso de pedagogia, cabe, então, indagar: qual será a força capaz de favorecer a ascensão do conhecimento próprio da pedagogia de modo que seu curso, ao privilegiar a teoria ou, pelo contrário, ao privilegiar a prática, não se restrinja apenas à formação de usuários de sistemas pedagógicos? 


\section{Referências}

AGUIAR, Márcia Angela da S.; MELO, Márcia M. Oliveira. Pedagogia e faculdades de educação: vicissitudes e possibilidades da formação pedagógica e docente nas IFES. Educação e Sociedade, v. 26, n. 92, p. 959-982, Especial - out. 2005.

BISSOLLI DA SILVA, Carmem. Curso de pedagogia no Brasil: história e identidade. Campinas: Autores Associados, 1999.

BOURDIEU, Pierre. 0 campo científico. In: ORTIZ, Renato (Org.). Pierre Bourdieu. São Paulo: Ática, 1983. p. 122-155.

FRANCO, Maria Amélia; LIBÂNEO, José Carlos; PIMENTA, Selma Garrido. Elementos para a formulação de diretrizes curriculares para cursos de pedagogia. Cadernos de Pesquisa, v. 37, n. 130, p. 63-97, jan. 2007.

HOUSSAYE, Jean. Pedagogia: justiça para uma causa perdida? In: HOUSSAYE, J. et al. Manifesto a favor dos pedagogos. Porto Alegre: ArtMed, 2004. p. 9-45.

HOUSSAYE, Jean et al. Manifesto a favor dos pedagogos. Porto Alegre: ArtMed, 2004.

KUENZER, Acácia Zeneida; RODRIGUES, Marli de Fátima. As diretrizes curriculares para o curso de pedagogia: uma expressão da epistemologia da prática. In: SILVA, Aida M. Monteiro et al (Orgs.). Novas subjetividades, currículo, docência e questões pedagógicas na perspectiva da inclusão social. ENCONTRO NACIONAL DE DIDÁTICA E PRÁTICA DE ENSINO, 8., 2006, Recife. Anais... Recife, 2006. p. 185-212.

LIBÂNEO, José Carlos. Diretrizes curriculares da pedagogia: imprecisões teóricas e concepção estreita da formação profissional de educadores. Educação e Sociedade, v. 27, n. 96, p. 843-876, Especial - out. 2006.

SAVIANI, Demerval. Pedagogia: o espaço da educação na universidade. Cadernos de Pesquisa, v. 37, nº 130, p. 99-134, jan. 2007.

SCHEIBE, Leda. Diretrizes curriculares para o curso de pedagogia: trajetória longa e inconclusa. Cadernos de Pesquisa, v. 37 , n.130, p. 43-62, jan. 2007.

SUCHODOLSKI, Bogdan. A pedagogia e as grandes correntes filosóficas. 2. ed. Lisboa: Livros Horizonte, 1978.

TANURI, Leonor Maria. As diretrizes curriculares do curso de pedagogia. In: BARBOSA, Raquel L. Leite (Org.). Formação de educadores: artes e técnicas, ciências e políticas. São Paulo: Editora UNESP, 2006. p. 73-81.

Recebido em: 13.10.2010

Aprovado em: 18.03.2011

Giseli Barreto da Cruz é professora adjunta do Departamento de Didática da Faculdade de Educação da Universidade Federal do Rio de Janeiro (UFRJ); pesquisadora do Laboratório de Estudos e Pesquisas em Didática e Formação de Professores (LEPED); pós-doutoranda em Educação pela Pontifícia Universidade Católica de São Paulo, sob a supervisão da professora Marli André; mestre e doutora em Educação pela Pontifícia Universidade Católica do Rio de Janeiro ${ }^{1}$, sob a orientação da professora Menga Lüdke; professora e pedagoga com larga experiência na educação básica, principalmente na rede pública de ensino.

1- ERRATA: A pedido da autora, fizemos a seguinte alteração no texto de sua biografia em 29.02 .2012 , deste modo, no arquivo publicado em ahead of print e html:

Onde se lê: "...doutora em Educação pela Pontifícia Universidade de São Paulo do Rio de Janeiro, sob a orientação da professora Menga Lüdke;"

Leia-se: "... doutora em Educação pela Pontifícia Universidade Católica do Rio de Janeiro, sob a orientação da professora Menga Lüdke;". 